\title{
Bending and Twisting Springback Prediction in the Punching of the Core for a Lattice Truss Sandwich Structure
}

\author{
Wenchun JIANG ${ }^{\dagger}$, Bin YANG, Xuewei GUAN and Yun LUO \\ State Key Laboratory of Heavy Oil Processing, College of Chemical Engineering, China University of Petroleum (East \\ China), Qingdao 266555, China
}

[Manuscript received 20 December 2012, in revised form 16 January 2013]

(c) The Chinese Society for Metals and Springer-Verlag Berlin Heidelberg

\begin{abstract}
The finite element method was used to study the springback induced by the punching of the core. In order to simulate the springback accurately, a mixed isotropic-nonlinear kinematic hardening model is used to define the material mechanical behavior during plastic deformation. The effects of the friction coefficient, the plate thickness and the die radius have been investigated. The results show that the springback of the sheet with diamond hole is different from the homogenous sheet. Not only bending springback, but also a twisting springback along the truss is generated because of the non-uniform distribution of the bending stress along the truss length. The plate thickness should be around $1.3 \mathrm{~mm}$ with larger friction coefficient and smaller die radius, which is useful to decrease the bending and twisting springback.
\end{abstract}

KEY WORDS: Plate with diamond hole; Punch; Springback

\section{Introduction}

Lightweight metallic sandwich panel structures consisting of low density cores and solid face sheets are widely used in aerospace applications, because they exhibit an attractive combination of the properties, such as low density, high strength, high specific stiffness, damping capacity, noise absorption, and multi-functional application potential, etc. ${ }^{[1-4]}$. The lattice truss sandwich panel structures are considered as the most promising type of structures for advanced lightweight materials because they are highly efficient load supporting systems ${ }^{[5]}$. The lattice truss topology is often fabricated by punching of a diamond hole plate ${ }^{[6-8]}$. But an elastic recovery called springback occurs because of the release of elastic stress $^{[9-12]}$. Springback is harmful because it not only brings the undesirable shape change, but also leads to

† Corresponding author. Assoc. Prof., Ph.D.; Tel: +86 532 86983482; Fax:+86 532 86983482; E-mail address: jiangwenchun@126.com (Wenchun JIANG)

DOI: $10.1007 / \mathrm{s} 40195-012-0268-0$ some difficulties in assembly ${ }^{[13-15]}$. And sometimes it can even decrease the material mechanical properties $^{[16-18]}$. For lattice truss sandwich structures, the springback will greatly affect on the final shape of brazing joint and has a corresponding effect on joint strength. Therefore, it is very important to predict the final shape to compensate springback.

In the past decade, a lot of researchers have been paid on springback by experimental ${ }^{[19-21]}$ and finite element methods $(\mathrm{FEM})^{[22-24]}$. With the development of computer technology, FEM has been considered as an effective way to predict springback. Chou and Huang ${ }^{[25]}$ used FEM to study the springback in U-channel bending processes, and the effects of four methods including arc bottoming, pinching die, spanking and movement techniques on springback reduction have been discussed. Ling et al. ${ }^{[26]}$ used FEM to study the effects of die clearance, die radius, step height and step distance on the springback in an Lbending of sheet metal, through which the die design recommendations were made. Panthi et al. ${ }^{[27]}$ studied the springback in a sheet bending, and a total-elasticincremental-plastic algorithm for large deformation 
and large rotational problem was incorporated in FEM. It was found that the springback increases with the increases of yield stress, strain hardening and sector angle, but it decreases with Young's modulus increase. In the open literatures, the homogeneous plates are used in most of the research objects. But it is not clear whether the sheet with a lot of diamond holes has a similar springback as the homogenous sheet. Therefore, this paper studies the springback of the plate with diamond holes used as the core of a lattice truss sandwich structure, and the effects of friction coefficient, plate thickness and die radius have been discussed, which is useful to decrease the springback.

\section{Finite Element Model}

In this paper, the springback simulation is realized by both implicit solution and the explicit solution methods. The punching is simulated by ABAQUS/Explicit and the springback analysis is modeled by ABAQUS/standard.

\subsection{Punching of the core}

Fig. 1 shows a photograph of the lattice truss sandwich panel structure ${ }^{[1]}$. It is made by brazing the core to face sheet. The core is usually made of perforating metal sheets to create a periodic array of diamond shaped holes, and then the diamond sheet is folded along rows of nodes to create the lattice truss structure, as shown in Fig. 2. The thickness of the brazing joint is always not homogeneous and shows a gradual increase from the middle to the fillet. The springback will affect the final joint shape greatly, therefore it is necessary to improve the joint strength by decreasing the springback.

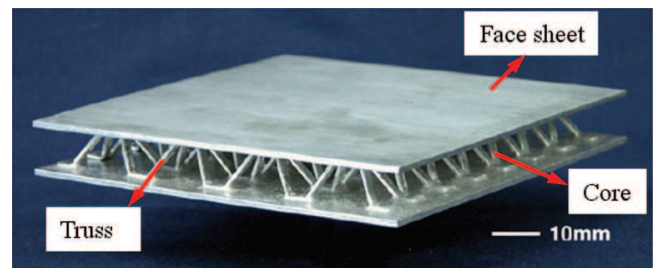

Fig. 1 Photograph of the lattice truss sandwich panel ${ }^{[1]}$

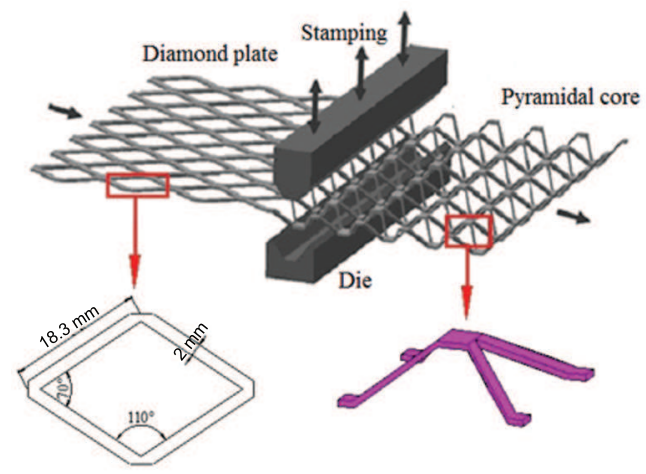

Fig. 2 Schematic diagram of the core punching

\subsection{Geometrical model and meshing}

Fig. 3 shows the schematic diagram of the finite element model, where $R=2 \mathrm{~mm}$ and $r=1 \mathrm{~mm}$ are die radius and punch nose radius, respectively. The punch and die are modeled as rigid body. The side of the diamond is $18.3 \mathrm{~mm}$, the truss width is $2 \mathrm{~mm}$, the plate thickness is $1 \mathrm{~mm}$, and the angle of diamond is $70^{\circ}$. The finite element meshing is shown in Fig. 4. The element type is a shell element S4R. In total, 16649 nodes and 14428 meshes are meshed.

\subsection{Material modeling}

The work hardening model plays an important role in the springback calculation. Taherizadeh et al. ${ }^{[28]}$ found that the combined isotropic-nonlinear kinematic hardening model was able to predict the springback more accurately than the isotropic hardening model. Zhang et al. ${ }^{[29]}$ also found that the isotropic hardening rule can over-predict springback because the predicted stress after forming is relatively larger, and the predicted results by non-linear combined hardening rule consist well with experimental data. Therefore, in this paper, the mixed hardening model is used to predict the springback, which hopes to get an accurate calculation result. The mixed hardening model contains the isotropic hardening and nonlinear kinematic hardening components. It allows the yield surface to either expand or contract and simultaneously translate.

The isotropic hardening component defines the evolution of the radius of the yield surface, $\sigma^{0}$, as

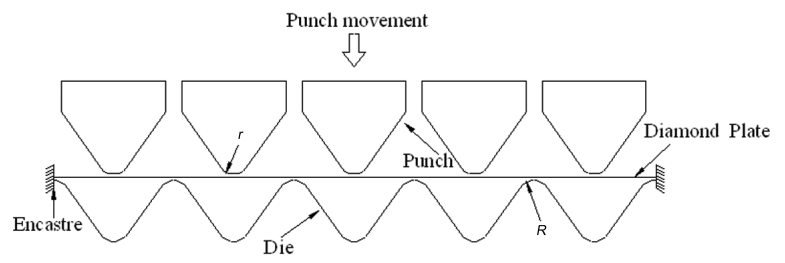

Fig. 3 Schematic diagram of the finite element model

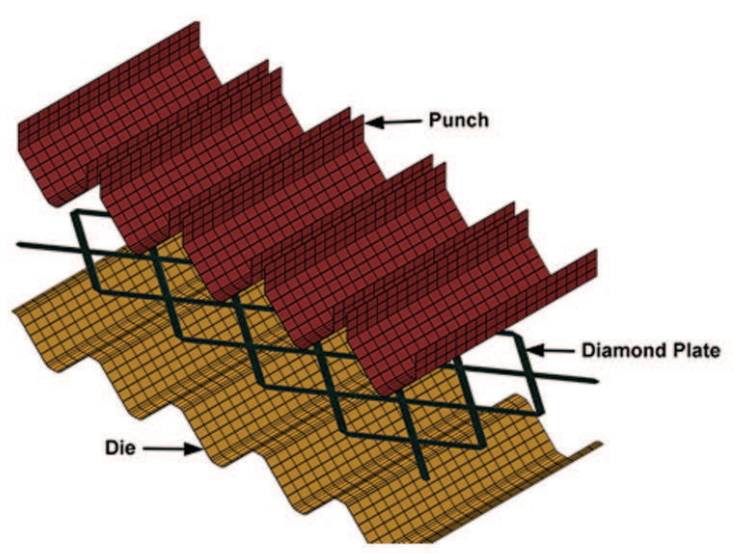

Fig. 4 Schematic diagram of finite element meshing 
a function of the equivalent plastic strain, which is defined as ${ }^{[30]}$ :

$$
\sigma^{0}=\sigma_{0}+Q\left(1-e^{-b \dot{\bar{\varepsilon}}^{\mathrm{pl}}}\right)
$$

where $\sigma_{0}$ is the yield stress at zero plastic strain; $\dot{\bar{\varepsilon}}^{\mathrm{pl}}$ is the equivalent plastic strain rate; $Q$ and $b$ are material parameters, $Q$ defines the maximum change of the radius of the yield surface and $b$ defines the rate at which the size of the yield surface changes as the plastic strain develops.

The kinematic hardening component, $\dot{\alpha}$, is defined as a combination of a kinematic term and a relaxation term. It is modeled by the translation of the yield surface in the stress space, implemented by the evolution of the shift of back-stress tensor, which is defined as $^{[30]}$ :

$$
\dot{\alpha}=\sum_{i}\left[C_{i} \frac{1}{\sigma_{0}}(\sigma-\alpha) \dot{\bar{\varepsilon}}^{\mathrm{pl}}-\gamma_{i} \alpha \dot{\bar{\varepsilon}}^{\mathrm{pl}}\right]
$$

where $C_{i}$ and $\gamma_{i}$ are material parameters; $\sigma$ and $\alpha$ are the stress and back-stress tensor. The required material parameters used in the mixed hardening modeling is listed in Tables $1^{[31]}$. In this mixed model, the yield surface is permitted to expand and translate as shown in Eq. (1), and the translation of the kinematic hardening component is specified by the parameter $\alpha$.

Table 1 Material parameters used in the mixed hardening model

\begin{tabular}{cccccccc}
\hline$\sigma_{0}(\mathrm{MPa})$ & $Q(\mathrm{MPa})$ & $b$ & $C_{1}(\mathrm{MPa})$ & $\gamma_{1}$ & \multicolumn{2}{c}{$C_{2}(\mathrm{MPa})$} & $\gamma_{2}$ \\
\hline 125.6 & 153.4 & 6.9 & 156435 & 1410.85 & 6134 & 47.19 \\
\hline
\end{tabular}

\subsection{Boundary and load conditions}

During the punching, the nodes on the both ends of the plate are completely fixed and a velocity of $1 \mathrm{~m} / \mathrm{s}$ is applied to the top punch.

\section{Results and Discussion}

\subsection{Springback prediction}

Fig. 5 shows the model shape before and after punching. It is shown that not only a bending springback, but also a twisting springback are generated as clearly shown in Figs. 6 and 7, respectively. For simplicity, we take the displacement, U, shown in Fig. 6, as the characterization of the bending springback. This is because $U$ has a great effect on the final shape of brazing joint. The offset angle before and after springback of the truss is taken as the characterization of twisting springback.

Fig. 8 shows the bending stress distribution along the truss length. It is shown that before the springback, the bending stresses are very large because of

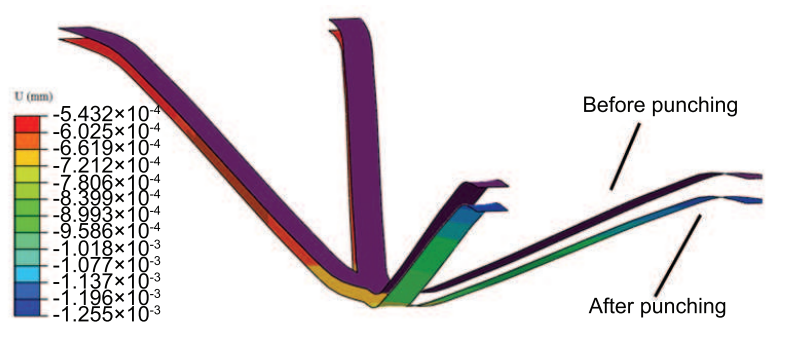

Fig. 5 The model shape before and after punching

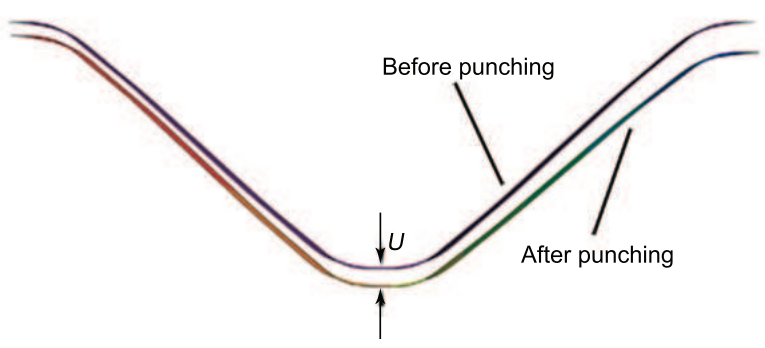

Fig. 6 Bending springback before and after punching

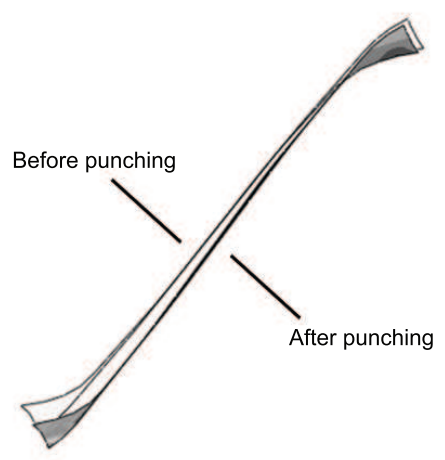

Fig. 7 Twisting springback before and after punching

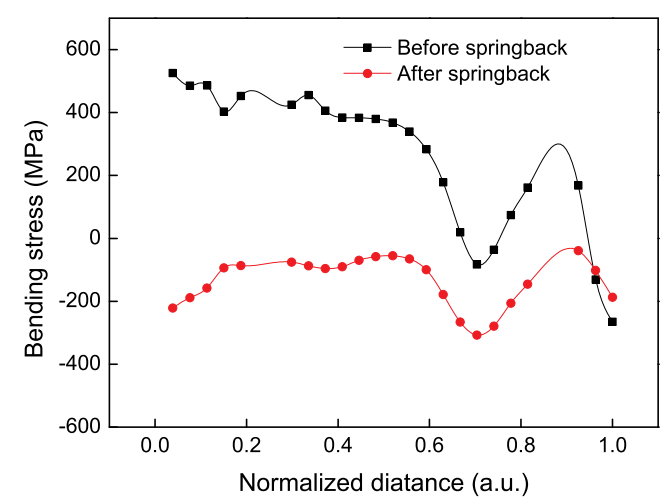

Fig. 8 Bending stress along the truss length before and after springback

the elastic and plastic deformation. The stresses distribute non-uniformly along the length, which is the reason for bending and twisting springback. Tensile and compressive stresses are generated respectively at the both ends of truss. After the springback, the residual stresses are released and become relatively uniform because of the deformation recovery. 
In order to reveal mechanism of the bending and twisting springback, a schematic of force diagram for a single truss $A B$ before springback, as shown in Fig. 9 , where $\mathrm{Fa}$ is positive stress at the end $A$, while $F_{\mathrm{b}}$ is a negative stress at the other end $B$. Then $\mathrm{Fa}$ is decomposed to $F_{1}$ and $F_{2}$, while $F_{\mathrm{b}}$ is decomposed to $F_{1}^{\prime}$ and $F_{2}^{\prime}$ in the plane of $A C B D$ and its vertical plane, respectively, as shown in Fig. $9 . F_{1}-F_{1}^{\prime}$ forms a couple and moment $M$ in plane $A C B D$, which leads to the springback. Before springback, the ends $A$ and $B$ are constrained rigidly by the punching die, which generates a constraint force $F_{\mathrm{c}}$ and $F_{\mathrm{c}}^{\prime}$, respectively, as shown in Fig. 9. Thus, $F_{\mathrm{c}}-F_{2}$ and $F_{\mathrm{c}}^{\prime}-F_{2}^{\prime}$ form a torque $T_{\mathrm{a}}$ and $T_{\mathrm{b}}$, respectively, which leads to the twisting. Therefore, the non-uniform stress distribution along the truss generates the moment and torque, which leads to the bending and twisting springback.

Fig. 10 shows the schematic of the bending stress distribution through plate thickness. Where $\rho_{1}, \rho_{2}$ and $\rho_{3}$ are the curvature radius of the outer, inner and the neutral layer surface, and $t$ is the plate thickness. At the beginning of bending, the relative bending radius $\rho_{2} / t$ is very large, and the plate only occurs the elastic bending, as shown in Fig. 10(a). The fiber of outer surface is tensile while the fiber of inner surface is compressive, and the surface of the bend zone has the maximum bending stress while the stress and strain in the neutral layer is zero. As the punch moves down, the value of $\rho_{2} / t$ is decreased continuously and bending deformation is increased

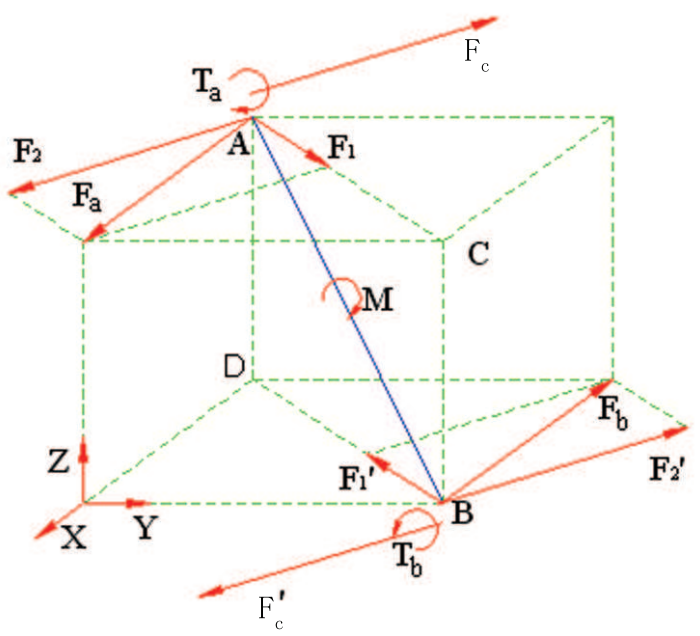

Fig. 9 Schematic of force diagram for a single truss

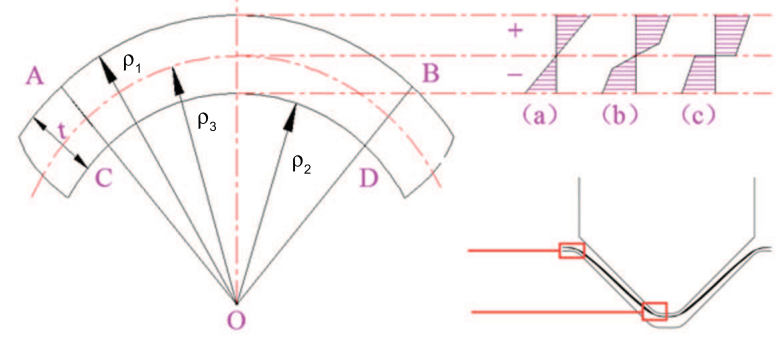

Fig. 10 Schematic of the bending stress gradually. The bending stresses on the surface reach the yield point firstly and spread into the center gradually, and the material is at elastic-plastic state at this time, as shown in Fig. 10(b). As the punching moves down further, $\rho_{2} / t$ continues to decrease and deformation increases, and all the material enters the plastic state, as shown in Fig. 10(c). Thus, with $\rho_{2} / t$ value decreases, the material changes elastic to plastic state and forms the permanent deformation finally. The springback is generated by the disappearance of the elastic deformation after removing the external load, which contains two cases. One case, as shown in Fig. $10(\mathrm{~b})$, is that as the $\rho_{2} / t$ is much larger, the inner and outer surface fiber enters the plastic state while the neutral layer remains elastic state, and the offloading generates springback. The other case is that the plastic deformation is always accompanied by the elastic deformation. Even if the inner and outer layer fibers are all plastic as shown in Fig. 10(c), the disappearance of elastic deformation will also generate the springback.

Therefore, deformation and stress are nonuniform, which produces the springback after it is uploaded. As a result, the bending angle and the curvature radius are changed, which affects the final shape of the bending parts. It is vital to control and decrease the springback. The friction coefficient, die radius and plate thickness have a great effect on the springback, which are discussed in the following.

\subsection{Effect of friction coefficient}

Fig. 11 shows the effect of the friction coefficient on the bending and twisting springback. It is shown that the both are decreased as the friction coefficient increases. This is because the compressive and tensile stresses are generated on the inner and outer surfaces, which lead to that the inner and outer fibers have a trend to elongate and shorten, respectively. After uploading, the materials were deformed toward the original shape. This shape recovery phenomenon is called springback. With the friction increase, the deformation area which has tensile stress increases. Deformation area makes the tensile stress state at both inner and outer surfaces, and has a negative effect on the

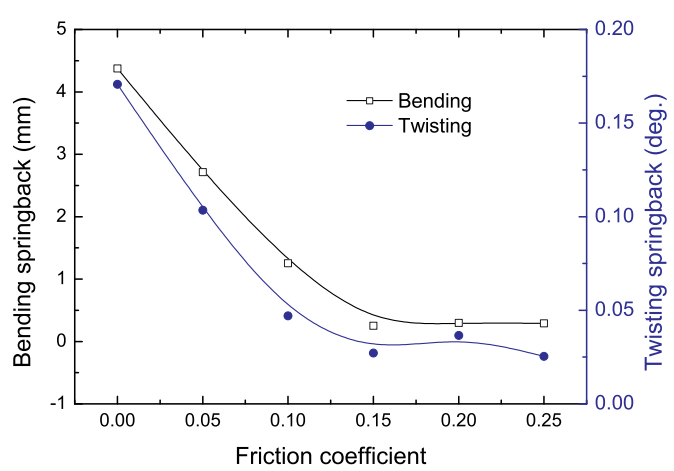

Fig. 11 Effect of the friction coefficient on springback 
shape recovery and decreases the springback.

\subsection{Effect of die radius}

Fig. 12 shows the effect of the die radius on the springback. It is shown that the springback and twisting are increased as the die radius increases. This is because at a certain punching angle, the greater the die radius the longer the deformation area. The tensile and compressive area on the inner and outer surfaces is increased, which leads to an increase of the springback. In addition, the stress along the section becomes more non-uniform as the die radius increases, which is also a reason for the increase of the springback.

\subsection{Effect of plate thickness}

Fig. 13 shows the effect of the plate thickness on springback for both bending and twisting. It is shown that the springback for both bending and twisting decreased firstly and then increased as the plate thickness increases. This is because the thicker plate can bring larger surface stress, and more materials have undergone plastic deformation, thereby decreasing the springback. But as the thickness increases to $1.3 \mathrm{~mm}$, the springback changes to increase. This is because at this case the material has entered the plastic stage, but there is still a small amount of elastic effect. It can be regarded that the

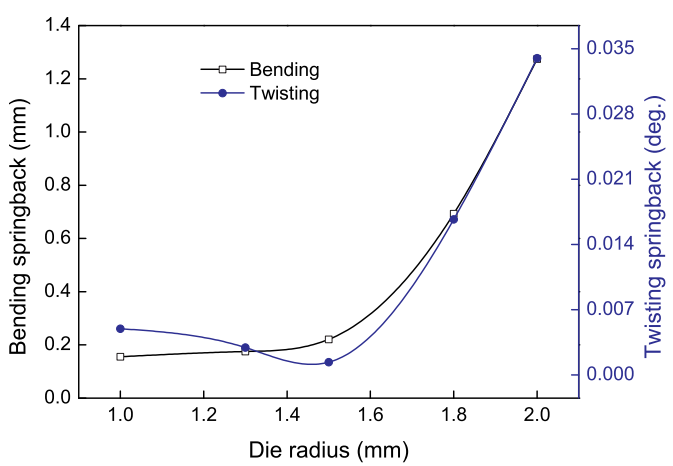

Fig. 12 Effect of die radius on the springback

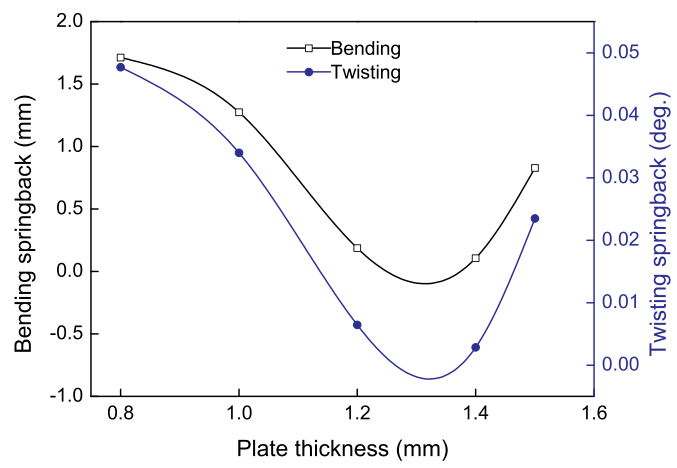

Fig. 13 Effect of plate thickness on springback elasticity of the plate with various thickness is the same, and the thicker the plate the stronger the accumulated elastic recovery, leading to the increase of springback. At the thicker plate, it is noteworthy that the material has a severe deformation, which increases the possibility of distortion and fracture. Therefore, the thickness can not be too thick and it can not exceed $1.3 \mathrm{~mm}$ in the core.

\subsection{Discussion}

From the above analysis, it is found that the springback of the present model is different from the homogenous sheet. For homogeneous plate, only bending springback is generated in the punching. But for the plate with diamond holes, the plate not only generates bending springback, but also the twisting springback is generated along the truss length. It is revealed that the bending stress along the truss length is not uniform and generates the bending moment and torque, which lead to the generation of the bending and twisting springback, respectively.

The bending and twisting springback have a great effect on the shape of brazing joint and brazing quality, the larger the springback, the more the nonuniform of joint thickness. It is found that some brittle phases are generated inevitably in the brazing joint and decrease the mechanical strength ${ }^{[32]}$, and it is also found that the joint thickness has a great effect on the strength and fracture ${ }^{[33]}$. Therefore, the increased springback can lead to a corresponding decrease of the mechanical strength. In order to decrease the springback, we discussed the effects of the friction coefficient, die radius and the plate thickness. The friction coefficient and die radius are related to the manufacture, and the plate thickness is related to the material design. It is found that as the friction coefficient increases the springback decrease, while the springback increase with the die radius increase. As the plate thickness increases, the springback are decreased firstly and then increased. The plate thickness should be around $1.3 \mathrm{~mm}$. Using the larger friction coefficient and smaller die radius is useful to decrease the springback.

\section{Conclusions}

In this study, the FEM was used to study the springback induced by punching to the core of lattice truss sandwich structure. The effects of friction coefficient, die radius and plate thickness on springback have been discussed. The obtained conclusions could be drawn as following.

(1) During the punching, two types of springback including bending springback and twisting springback are generated, because the bending stress along the truss length is not uniform.

(2) The springback is decreased with the friction coefficient increase, while the springback is increased 
with the die radius increase. As the plate thickness increases, the springback dereases firstly and then increases.

(3) In order to decrease the springback, it is proposed that the plate thickness should be around $1.3 \mathrm{~mm}$ with the larger punching friction coefficient and smaller die radius.

\section{Acknowledgements}

This work was supported by the National Natural Science Foundation of China (No.51105380), Doctoral Program of Higher Education of China (No.20100133120008), Natural Science Foundation of Shandong Province (No.ZR2010AQ002), Fundamental Research Funds for the Central Universities (No.10CX04030A) and Key Laboratory of Pressure System and Safety (MOE), East China University of Science and Technology.

\section{REFERENCES}

[1] W.G. Kooistra and H.N. Wadley, Mater. Des. 28 (2007) 507.

[2] T.D. Queheillalt and H.N.G. Wadley, Mater. Des. 30 (2009) 1966.

[3] Q.C. Zhang, Y.J. Han, C.Q. Chen and T.J. Lu, Sci. China E: Technol. Sci. 52 (2009) 2147.

[4] Q.C. Zhang, A.P. Chen, C.Q. Chen and T.J. Lu, Sci. China E: Technol. Sci. 52 (2009) 2670.

[5] T.D. Queheillalt, G. Carbajal, G.P. Peterson and N.G.H. Wadley, Int. J. Heat Mass Transf. 51 (2008) 312.

[6] W.G. Kooistra, S.V. Deshpande and N.G.H. Wadley, Acta Mater. 52 (2004) 4229.

[7] T.D. Queheillalt and N.G.H. Wadley, Mater. Sci. Eng. A 397 (2005) 132.

[8] W.C. Jiang, H. Chen, J.M. Gong and S.T. Tu, Mater. Sci. Eng. A 528 (2011) 4715.

[9] S. Chatti and N. Hermi, Comput. Struct. 89 (2011) 1367.

[10] K.P. Li, W.P. Carden and R.H. Wagoner, Int. J. Mech. Sci. 44 (2002) 103.

[11] P. Xue, T.X. Yu and E. Chu, Int. J. Mech. Sci. 43 (2001) 1893.
[12] A.S. Asgari, M. Pereira, B.F. Rolfe, M. Dingle and P.D. Hodgson, J. Mater. Process. Technol. 203 (2008) 129.

[13] W. Gan and H.R. Wagoner, Int. J. Mech. Sci. 46 (2004)1097.

[14] S.H. Cheng, J. Cao and Z.C. Xia, Int. J. Mech. Sci. 49 (2007) 267

[15] H. Naceur, Y.Q. Guo, L.J. Batoz and C. Knopf-Lenoir, Int. J. Mech. Sci. 43 (2001) 2407.

[16] Z.Q. Jiang, H. Yang, M. Zhan, X.D. Xu and G.J. Li, Mater. Des. 31 (2010) 2001.

[17] K. Yilamu, R. Hino, H. Hamasaki and F. Yoshida, J. Mater. Process. Technol. 210 (2010) 272.

[18] H.R. Wagoner and M. Li, Int. J. Plast. 23 (2007) 345

[19] A. Mkaddem and D. Saidane, J. Mater. Process. Technol. 189 (2007) 325.

[20] S.H. Kim and M. Koc, J. Mater. Process. Technol. 204 (2008) 370.

[21] G. Ingarao, D.R. Lorenzo and F. Micari, Mater. Des. 30 (2009) 4421.

[22] E. Daxin and Y.F. Liu, Mater. Des. 31 (2010) 1256.

[23] R. Kazan, M. Firat and E.A. Tiryaki, Mater. Des. 30 (2009) 418

[24] S. Thipprakmas, Mater. Des. 31 (2010) 1593.

[25] I.N. Chou and C. Hung, Int. J. Machine Tools Manuf. 39 (1999) 517.

[26] Y.E. Ling, H.P. Lee and B.T. Cheok, J. Mater. Process. Technol. 168 (2005) 296.

[27] S.K. Panthi, N. Ramakrishnan, M. Ahmed, S.S. Singh and M.D. Goel, Mater. Des. 31 (2010) 657.

[28] A. Taherizadeh, A. Ghaei, E.D. Green and W.J. Altenhof, Int. J. Mech. Sci. 51 (2009) 314.

[29] D.J. Zhang, Z.S. Cui, X.Y. Ruan and Y.Q. Li, Comput. Mater. Sci. 38 (2006) 256.

[30] F.W. Brust, T. Zhang, D.J. Shim, S. Kalyanam and G. Wilkowski, Proceedings of the ASME 2010 Pressure Vessels \& Piping Division, Bellevue, Washington, USA, July 18-22, 2010.

[31] O. Muránsky, C.J. Hamelin, M.C. Smith, P.J. Bendeich and L. Edwards, Comput. Mater. Sci. 54 (2012) 125.

[32] W.C. Jiang, J.M. Gong and S.T. Tu, Mater. Des. 31 (2010) 2157.

[33] W.C. Jiang, J.M. Gong and S.T. Tu, Mater. Des. 31 (2010) 2387. 